\title{
ИННОВАЦИОННОЕ РАЗВИТИЕ РОССИЙСКОЙ ЭКОНОМИКИ: ТЕНДЕНЦИИ, ПРОБЛЕМЫ, ПЕРСПЕКТИВЫ
}

\author{
С. В. Кочетков, О. В. Кочеткова \\ Межрегиональная Санкт-Петербурга и Ленинградской области \\ Общероссийская общественная организация «Вольное экономическое общество России»
}

Поступила в редакцию 4 ноября 2019 г.

\begin{abstract}
Аннотация: исследовано состояние инновационного развития российской экономики, выявлены и обоснованы тенденциии снижения объёма инноваџчонных товаров, работ, услуг. С позиций оценки потенцииала научных исследований и потенцииала внедрения их результатов в производство определены ключевые проблемы инновачионного развития нашей экономики. В ичелях обеспечения научно-технологического прорыва сформулирован комплекс мер и предложен механизм его реализации.
\end{abstract}

Ключевые слова: инновационное развитие, инновационные товары, работы, услуги, потенциал научных исследований, потенциал внедрения результатов научных исследований в производство, научно-технологический прорыв.

\begin{abstract}
Russian economy. Identified and justified trends in reducing the volume of innovative goods, works, services. From the standpoint of assessing the capacity of scientific research and the capacity for introducing their results into production, the key problems of the innovative development of our economy are identified. In order to ensure a scientific and technological breakthrough, a set of measures has been formulated and a mechanism for its implementation has been proposed.
\end{abstract}

Key words: innovative development, innovative goods, works, services, research potential, potential for introducing research results into production, scientific and technological breakthrough.

Последнее десятилетие знаменуется переходом производительных сил современного мира на новую ступень. И наша страна в этом вопросе старается не отставать. В настоящее время подготовлена и принята к реализации Стратегия научно-технологического развития России [1], а также действуют другие стратегии, призванные обеспечить переход российской экономики к новым стратегическим рубежам. Вместе с тем подчеркнём, что в довольно внушительном, беспрецедентном составе, например по охвату, масштабам и размерам финансирования, действующих сегодня национальных проектов развития экономики и общества отсутствует в отдельной интерпретации такое важное направление, как промышленность [2]. Выражаем уверенность, что в ближайшее время этот недостаток будет устранён в том или ином виде. К примеру, таким образом [3; 4]. В подтверждение этому высказывается В. А. Мау. Он утверждает, что в современных условиях в России формируется новая модель экономического роста, одним из важнейших элементов которой выступает переход от стимулирования спроса к стимулированию предложения [5].

(C) Кочетков С. В., Кочеткова О. В., 2020
Раздвигая рамки использования современных достижений науки, техники и технологий, инновационное состояние нашей экономики в её нынешнем виде открывает возможности не только для усиления роли науки в воспроизводстве, но и значительного роста производства. Отсюда радикальные изменения в номенклатуре конечной и промежуточной продукции, продукции производственного и потребительского назначения; во взаимоотношении между производством вещей и услуг; в структуре всех звеньев воспроизводственного процесса (производство, распределение, обмен и потребление); в системах управления; в масштабах и направлениях международных экономических связей; в занятости и характере труда и образования.

Едва ли не важнейшей особенностью современного этапа развития экономики является постоянное вовлечение науки в процессы роста производства. В своём выступлении Президент Российской Федерации В. В. Путин на заседании Совета при Президенте по науке и образованию особо отметил: «...мы вместе... определим дальнейшие шаги по укреплению и, главное, качественному развитию научного потенциала страны, чтобы он 
в полной мере соответствовал масштабным задачам, задачам прорыва, которые стоят перед Россией...» [6]. В этих условиях цель нынешней экономической политики государства должна состоять в том, чтобы в короткие сроки выйти на самые передовые научно-технические рубежи, на высший мировой уровень производительности труда - обеспечить научно-технологический прорыв в экономическом и социальном развитии.

Решению данной задачи должно способствовать укрепление взаимосвязей между научным заделом, потенциалом и производственными возможностями нашей экономики. При этом необходимо иметь в виду, что автоматической зависимости между наукой, техникой и технологией и их применением в производственном процессе, изменениями в структуре воспроизводства, переменами в жизни общества не существует и что в различных проявлениях инновационного состояния экономки неизбежны разрывы, которые превращаются в противостояние и противоборство разнонаправленных сил, а выдающиеся, в некоторых случаях прямо-таки ошеломляющие успехи науки и техники зачастую оказываются не в состоянии переломить отрицательные тенденции, возникающие на почве разобщённых, разрозненных связей с резуль- татами их использования в производстве. В ходе изменений инновационного состояния присущая этому конфликтная неравномерность нередко проявляется в новых, неизвестных ранее формах и по многим направлениям обостряется. Само содержание инновационного состояния на современном этапе свидетельствует о том, что российская экономика находится на переломе, когда новое ещё не устоялось, и потому его изучение сопряжено с большими трудностями.

Инновационное развитие экономики характеризуется способностью создавать на основе достижений науки новые материалы, обладающие ранее неизвестными свойствами, новые технологические процессы, новые, более совершенные машины и другие изделия.

Направление, по которому реализуется возрастающее влияние инновационного состояния на приведение экономической структуры в соответствие с новыми реалиями воспроизводства, связано с принятием подлинно революционных мер в целях создания прочного, стойкого фундамента науки и производства. В этих условиях вопрос интеграции науки и производства имеет большое значение в ускорении темпов роста производства инновационных товаров, работ, услуг (рис. 1).

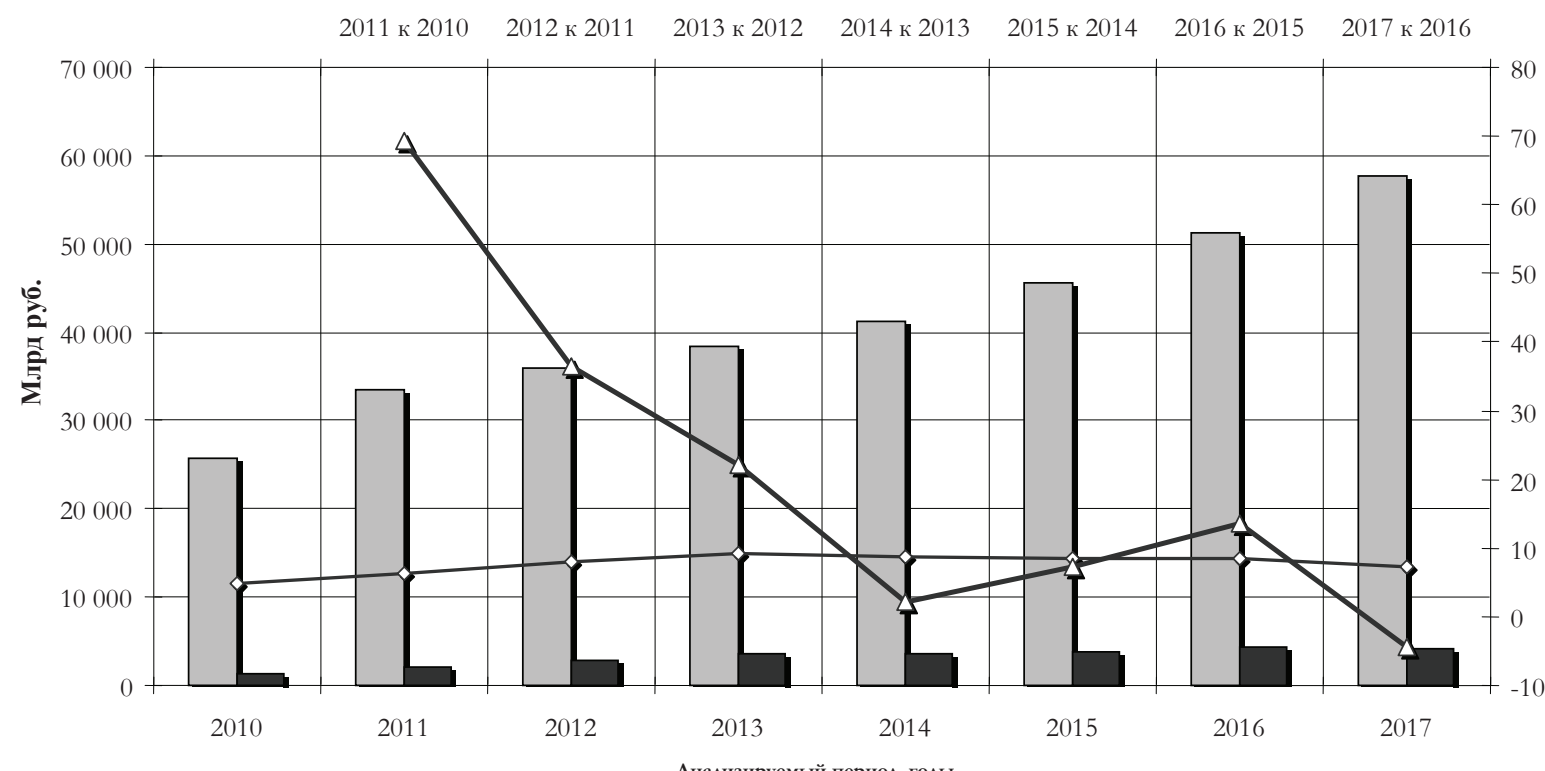

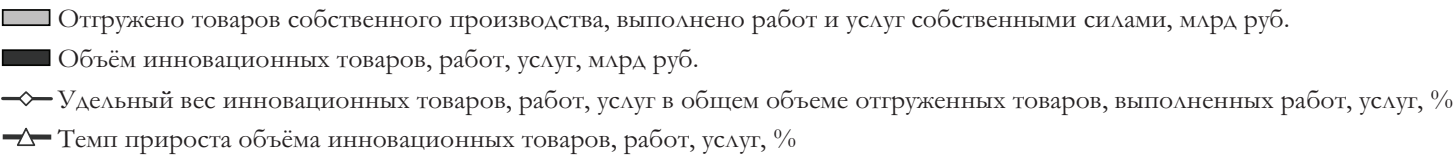

Puc. 1. Внешняя характеристика инновационного состояния российской экономики (рассчитано авторами по данным Росстата) 
Данные рис. 1 показывают значительное снижение темпов роста производства инновационных товаров, работ, услуг в нашей стране вплоть до отрицательного значения за последний анализируемый год. Как можем видеть, и их удельный вес находится в относительно перманентном состоянии.

Объясняется это следующими причинами. При выстраивании системы кооперации между процессами научных исследований и внедрением их результатов в производстве у нас практически отсутствует прямое взаимодействие и координация усилий между профильными министерствами, ведомствами и органами власти в регионах и особенно промышленными предприятиями. Ещё одна сторона - остаются нерешёнными вопросы измеримости поставленных целей и, самое главное, ответственности за полученные результаты. Здесь имеется и ряд других причин, но менее важных, вытекающих из указанных. Запустить такой механизм нужно в самое ближайшее время.

В связи с ориентацией на приоритеты Стратегии научно-технологического развития, переходом на реализацию национальных проектов по-новому должна решаться и задача соединения научных исследований и производства. В данном случае, на наш взгляд, первичным звеном, единицей экономики может выступить научно-производственный комплекс и должен это сделать. Крупные производственные комплексы получают большие возможности по созданию в своём составе научно-исследовательских подразделений, лабораторий, которые более эффективно организуют работу по совершенствованию техники и технологии, существенно ускоряют внедрение технических новинок. Как показывает практика, часто слабым звеном в цепи «исследование внедрение» является фаза «научная организация - предприятие» [7]. Задача этой фазы - доведение разработки или образца новой техники, созданных в научной организации, до стадии серийного производства; доработка опытного образца, выпуск малой серии, изготовление инструментов, оснастки и оборудования. Данную функцию могут выполнять специализированные объединения по внедрению новой техники, которые могут быть созданы в рамках научно-исследовательских подразделений производственных комплексов.

В наши дни инновационное состояние связано с появлением новых возможностей для развития экономики. Разумеется, количество выпущенных изделий также имеет значение, так как оно определяет масштаб внедрения новой техники и технологий, однако это не меняет основного положения: инновационное развитие выражается темпами воспроизводства инновационных товаров, работ, услуг.

Мы рассмотрели внешнюю сторону инновационного состояния российской экономики. Для выявления факторов, влияющих на рост объёма инновационных товаров, работ, услуг, изучим внутреннюю структуру инновационного состояния.

Сердцевиной всех мер по изменению экономической структуры является повышение эффективности науки и внедрения её результатов в производство. Получаемые нами инновационные товары, работы, услуги - это следствие технического развития, а истоки научно-технологического прорыва скрываются в науке, в её достижениях [8]. Науке в самом широком плане, реализуемой во всех звеньях творческой цепи - от академических и других институтов, научных исследований в высших учебных заведениях, отраслевых научных организациях (ожидаем возрождения), подразделений так называемой «заводской науки» и заканчивая международными научно-техническими связями [9].

Наука и освоение её достижений в экономике являются основными источниками роста производства инновационных товаров, работ, услуг. Сегодня, как никогда, следует указать на необходимость всемерного повышения эффективности науки, реализации её успехов. Претворение в жизнь этих указаний представляет собой дело огромного исторического значения на современном этапе - обеспечение научно-технологического прорыва в развитии нашей экономики и общества.

В связи с этим внутренняя структура инновационного состояния экономики характеризуется следующими моментами. Потенциал научных исследований выражается объёмом спроектированных и сконструированных опытных изделий, т. е. долей разработок во внутренних текущих затратах на научные исследования и разработки, осуществляемые в нашей стране (рис. 2).

Как видно из рис. 2 , средства, вкладываемые в разработки, дают перманентный положительный эффект. При этом их величина со временем достаточно стабильно увеличивается при повышении затрат в целом на научные исследования, что очень 


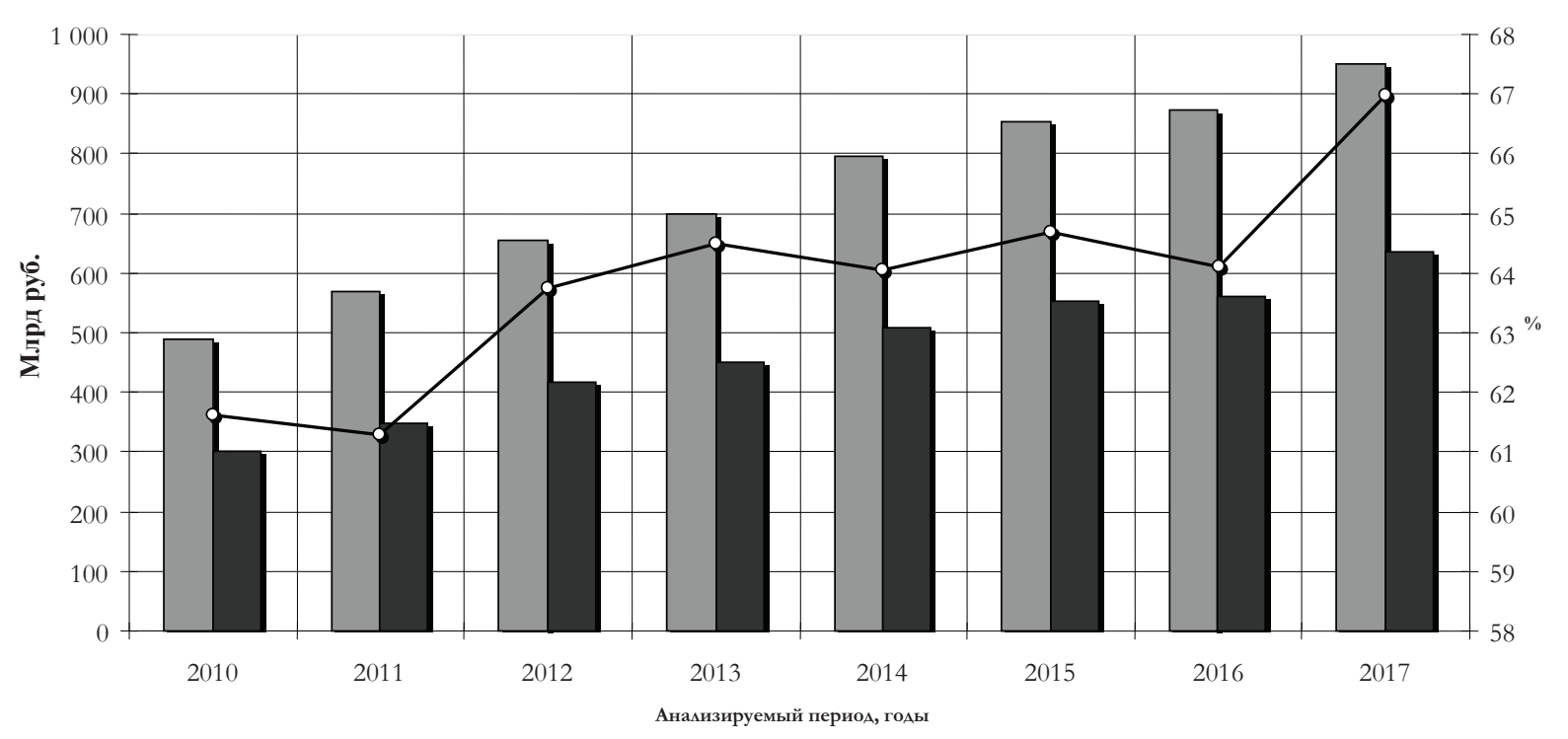

\footnotetext{
$\square$ Внутренние текущие затраты на научные исследования и разработки, в том числе по видам работ: фундаментальные исследования прикладные исследования, разработки, млрА руб́.

Разработки, мАра руб.

—-УАельный вес разработок во внутренних текущих затратах на научные исследования и разработки, \%
}

Puc. 2. Потенциал научных исследований в Российской Федерации (рассчитано авторами по данным Росстата)

важно в рамках предъявляемых требований к науке в нынешних условиях функционирования нашей экономики. В то же время следует отметить тот факт, что сегодня некоторые перспективные задачи, принципиального характера, очень часто не формулируются государством.

Профильные министерства практически всегда не имеют никакого отношения не только к решению таких задач, но и к их постановке. Прерогатива исследуемых проблем находится в руках научно-исследовательских подразделений, лабораторий. Налицо отсутствие не только прямого, но и косвенного взаимодействия между государством и научными организациями. Исходя из этого, тематика фундаментальных и поисковых научных исследований не меняется довольно продолжительное время и, что самое главное, не согласуется не только с соответствующими органами власти, но и практикой хозяйствования. В дополнение к этому в подобных случаях конечные результаты не просматриваются вообще. Именно подобное взаимодействие увеличивает процент внедрения результатов научных исследований в производство.

Несмотря на высокую экономичность науки, мы не можем удовлетвориться её результатами, и надо сделать всё возможное для повышения темпов роста производства инновационных товаров, работ, услуг.
Для полноты картины представим, как обстоит дело в отечественной экономике в части внедрения результатов научных исследований в производство.

По мере расширения научной деятельности и увеличения объёма новых знаний проблема их рационального использования приобретает сегодня всё большее значение. Практическое внедрение новых научных идей - в нынешних условиях не менее важная задача, чем их разработка.

Внедрение достижений науки и техники в производство встречает известное «сопротивление». Наличие такого «сопротивления» диалектически присуще этому процессу. В то же время «характер сопротивления» и его «величина» могут быть весьма различными. В некоторых случаях усиление для преодоления «сопротивления» может быть практически незаметным, в иных может стать непреодолимым препятствием. Однако в любом случае процесс внедрения не может идти сам собой. В зависимости от конкретных условий он требует тех или иных действий, усилий. Здесь, рассматривая вопросы практического использования достижений науки и техники в производстве, следует иметь в виду возможность возникновения затруднений различного рода, предвидеть их характер, возможные последствия и с учётом этого так организовать процесс внедрения, чтобы добиться минимума затрат ресурсов на его реализацию. 
Выявление и анализ причин, затрудняющих своевременное и полное использование достижений науки в производстве, даёт возможность при разработке методов и форм организации внедрения результатов научных исследований и разработок найти пути, уменьшающие или исключающие воздействие отрицательных факторов.

Важнейшим проявлением действия этих факторов является доля внедрения результатов научных исследований в производство в нашей стране (рис. 3).

Преодолеть их влияние сегодня и переломить негативную тенденцию (снижения) внедрения результатов научных исследований в производство, а затем повысить его долю возможно, сосредоточив усилия на направлениях, которые соответствуют государственным целям и приоритетам Стратегии научно-технологического развития. В связи с этим нужно использовать механизм крупных исследовательских программ с измеримыми целями и прозрачными результатами и, самое главное, ответственностью за их достижение. Данный программный подход позволит исключить дублирование функций, поставить чётко сформулированные и понятные задачи перед академическими институтами и вузовской наукой, государственными и частными предприятиями и организациями, от- дельными научными подразделениями и лабораториями. И, как отмечалось ранее, по возможности быстрее ввести в действие механизм взаимодействия профильных министерств, органов государственной власти субъектов Российской Федерации и промышленных предприятий. Кроме этого, нужно в полной мере задействовать потенциал формирующихся научно-образовательных центров как ресурса технологического и пространственного развития нашей страны.

Становится очевидным, что внутренняя структура инновационного состояния экономики зависит от рассмотренных нами параметров - потенциала научных исследований и потенциала внедрения их результатов в производство. В связи с этим затраты (входящие в состав данных параметров при расчёте) являются именно теми факторами, которые оказывают влияние на рост объёма инновационных товаров, работ, услуг в нашей стране.

Нам интересны затраты на научные исследования (фундаментальные исследования, прикладные исследования и разработки), затраты, сопряженные с внедрением их результатов в производство (приобретением машин и оборудования, связанных с технологическими инновациями, новых технологий) и затраты на технологические (продуктовые, процессные) инновации и на развитие промышлен-

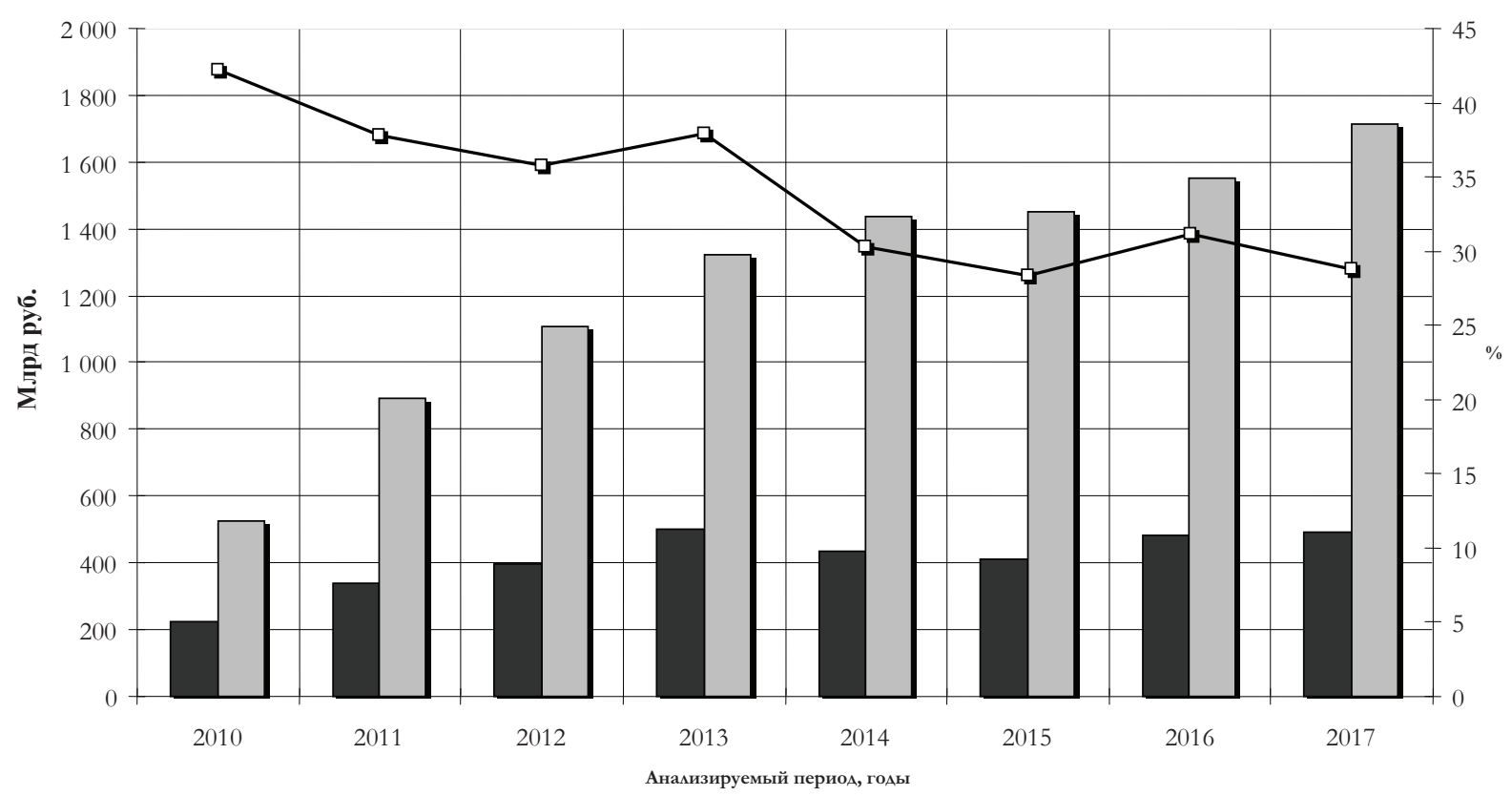

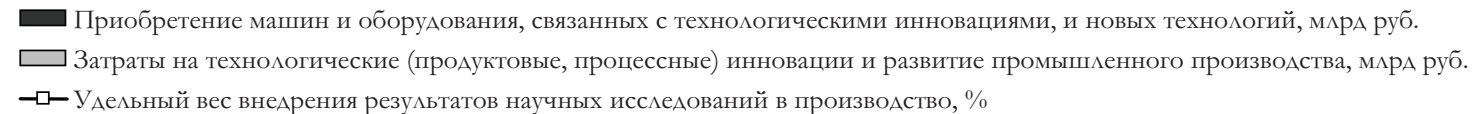

Puc. 3. Потенциал внедрения результатов научных исследований в производство в Российской Федерации (рассчитано авторами по данным Росстата) 
ного производства. В первом случае мы должны говорить об эффективности затрат для проектирования и конструирования опытных образцов, а во втором - об эффективности затрат на производство инновационных товаров, работ, услуг, т. е. выяснить далее, как может быть использован их потенциал для обеспечения научно-технологического прорыва - устойчивого темпа роста инновационных товаров, работ, услуг.

Опираясь на эту основу, можно с уверенностью сказать, что инновационное состояние экономики определяется входными характеристиками: затратами на научные исследования и затратами на внедрение их результатов в производство. На выходе инновационное состояние выражается объёмом инновационных товаров, работ, услуг. Подчеркнём, что инновационное состояние экономики с математической точки зрения можно определить как вклад этих затрат в рост объёма инновационных товаров, работ, услуг.

Возможность в государственных интересах постоянно воздействовать на инновационное состояние экономики составляет одно из решающих преимуществ реализации процессов научно-технологического прорыва в нашей стране. Чтобы полнее использовать данную возможность, надо прежде всего усилить комплексность и целенаправленность интеграции науки и производства, постоянно повышать его научную обоснованность, при этом формируя нужную структуру инновационного состояния экономики с целью обеспечения устойчивости роста инновационных товаров, работ, услуг.

На основе проведённого исследования получены следующие результаты.

Вся логика исследования подтверждает, что инновационное состояние экономики - это состояние, при котором использование потенциала научных исследований и внедрения их результатов в производство обеспечивает воспроизводство инновационных товаров, работ, услуг. Иными словами, задача заключается в том, чтобы выяснить уровень влияния затрат на научные исследования и внедрение их результатов в производство на рост объёма инновационных товаров, работ, услуг, а также их вклад в темп прироста инновационных товаров, работ, услуг.

Несмотря на огромное количество предпринимаемых усилий в нашей стране, увеличение затрат на научные исследования (почти двукратное увеличение с 489,45 млрд руб. в 2010 г. до 950,26 млрд руб. в 2017 г.) и на внедрение их результатов в производство (с 749,22 млрд руб. до 2209,76 млрд руб. за период с 2010 по 2017 г.), темп прироста инновационных товаров, работ, услуг неуклонно снижается (с 69,39 \% в 2010-2011 гг. до 13,55 \% в 2015-2016 гг., а в 2016-2017 гг. наблюдалось снижение - на 4,52 \%).

Вместе с тем считаем важным отметить, что достигнутый потенциал научных исследований хотя и незначительно, но увеличивается с 61,61 до 66,97 \% в 2010-2017 гг. В то же время за этот период доля внедрения результатов научных исследований в производство по-прежнему уменьшается (с 42,21 \% в 2010 г. до 28,79\% в 2017 г.).

Полученные результаты исследования позволяют сделать следующие выводы.

Можно без всякого преувеличения сказать, что на сегодня (при современном инновационном состоянии российской экономики) ставить вопрос о научно-технологическом прорыве представляется как никогда своевременным. Определённый научный потенциал и производственная база создали основу для перехода к преимущественно интенсивному развитию науки и техники. Следовательно, можно с уверенностью утверждать, что достигнутый уровень инновационного состояния нашей экономики не только готов, но и способен обеспечить научно-технологический прорыв в ближайшей перспективе.

Всё это служит наглядным доказательством того, что для осуществления воздействия на нынешнее инновационное состояние российской экономики нужно, как мы считаем, довольно пристальное внимание со стороны государства в виде централизованного управления наукой в нашей стране и разработки ещё одного, тринадцатого, национального проекта - программы «Организация и управление промышленностью». Полагаем целесообразным напомнить, что именно промышленность, как одна из ключевых отраслей экономики, является её магистральным локомотивом. Как мы выяснили, все предпосылки для этого имеются и предоставляемыми возможностями следует немедленно воспользоваться. По нашему глубокому убеждению, так называемые «частники» непременно сами захотят принять в нём активное участие.

В определённом смысле централизованное управление наукой в нашей стране начинает реализовываться. РАН наделена, кроме других, новыми полномочиями по прогнозированию основных направлений научного, научно-технического и социально-экономического развития страны. Надо полагать, что академия становится той площадкой, на 
которой обеспечено, с точки зрения науки, вот такое стратегическое планирование. В дополнение к этому в настоящее время ведётся активная работа по созданию механизмов взаимодействия Министерства науки и высшего образования Российской Федерации с федеральными органами исполнительной власти и органами государственной власти субъектов Российской Федерации по вопросам научного обеспечения реализации национальных проектов (программ) и документов стратегического планирования с учётом приоритетов научно-технологического развития Российской Федерации [10].

Чрезвычайно показателен тот факт, что в нашей стране начинает свою работу, кроме других направлений, рабочая группа Государственного совета Российской Федерации по направлению «Промышленность» [11]. Полагаем, что для разрешения выявленных в работе противоречий следует объединить усилия в рамках данной рабочей группы по реализации промышленной политики в нашей стране [12], в первую очередь по созданию крупных промышленных комплексов [13]. Упорядочить эту работу и создать одну из ведущих отраслей в российской экономике и должен быть призван новый национальный проект «Организация и управление промышленностью». Кроме прочего, в нём следует систематизировать стратегии развития нашей страны по такой ключевой отрасли промышленности, как машиностроение [14].

Ответы на поставленные вопросы очевидны. Мы постараемся их обобщить и конкретизировать.

Сказанное определяет необходимость системного управления наукой и производством. В самом общем виде оно предполагает разработку конкретных целей и критериев эффективности научно-технологического развития; создание системы специальных органов, занимающихся его управлением, и постоянное её совершенствование; осуществление таких специфических функций управления, как планирование, финансирование, стимулирование процессов научно-технического развития, организация научно-исследовательских работ и мероприятий по освоению новой техники и реализации новой продукции.

Подобное предложение давно назрело. Ещё академик Академии наук СССР Е. М. Примаков, выступая на пленарной дискуссии № 1 «Реиндустриализация в мире. Новая промышленная политика против финансовых спекуляций и экономического застоя» в рамках Московского экономического форума (МЭФ-2014) [15], отвечая на вопрос: «Как обеспечить развитие?», утверждал, что, кроме прочего, необходимо выработать программу государственного участия в технико-технологическом прогрессе нашей экономики и высказался в поддержку воссоздания Государственного комитета СССР по науке и технике (ГКНТ СССР) с учётом современных реалий функционирования российской экономики. Этого же мнения придерживается и нынешний президент РАН, академик А. М. Сергеев. В одном из своих недавних выступлений о роли науки, и в частности академии, в экономическом и социальном развитии нашей страны он особо подчеркнул: «Нам нужно сообща взяться за развитие отечественной науки, выстроить скоординированную цепочку. Необходимо понять, что наука без промышленности не живёт, как и промышленность без науки» [16].

В современных условиях в основе этой системы, на наш взгляд, должен стоять единый план науки и производства, обеспечивающий своевременное выполнение задач, выдвигаемых государством, - научно-технологический прорыв, и создание научно-технического задела на будущее. Такой план становится ничем иным, как механизмом реализации предлагаемых мероприятий.

Всё это убедительно доказывает, что успешное воздействие на инновационное состояние экономики возможно лишь в условиях комплексности и целенаправленности планирования интеграции науки и производства.

Если говорить о комплексности, она означает в первую очередь увязку в планах, с одной стороны, технических и экономических аспектов развития, a c другой - всех стадий продвижения опытных образцов из сферы науки в хозяйственную практику. Данным двум направлениям комплексности соответствует осуществление двух крупных мероприятий - введения в план развития науки и производства экономических показателей и разработки комплексных программ по наиболее важным научно-техническим проблемам. Это поможет избежать рассогласования между планом развития науки и производства и другими программами, реализуемыми в настоящее время в нашей стране.

В чём же выражается целенаправленность данного процесса? Увязать единый план науки и производства с имеющимися программами позволит система экономических показателей. Причём, выполняя эту функцию, система экономических показателей одновременно способствует и усилению целевой направленности единого плана науки и производства, ведь, как все мы понимаем, научно-технологический прорыв не является самоце- 
лью. Сегодня, впрочем, как и в ближайшей, так и долговременной перспективе, он выступает лишь в качестве средства достижения определённых конечных целей экономического и социального развития нашей страны. В связи с этим экономические показатели как раз и призваны отразить вклад развития науки и техники в достижение итоговых параметров развития. Мы видим, что система экономических показателей должна стать основным содержанием начальной, так сказать, «целевой» стадии единого плана науки и производства.

Разумеется, что более эффективному использованию результатов науки будет способствовать включение в имеющиеся сегодня программы экономического и социального развития нашей страны специального раздела по внедрению новой техники и выделению в нём основных заданий по выполнению научно-технических программ, по разработке и освоению новых высокоэффективных технологических процессов и видов продукции и других показателей, характеризующих темпы прироста инновационных товаров, работ, услуг. И начать следует с закона о стратегическом планировании [17], включив в него собственно единый план науки и производства. Тем самым этот федеральный закон может быть реанимирован, а его механизмы приведены в действие. Включение единого плана науки и производства является двигателем федерального закона о стратегическом планировании в нашей стране. В результате этого он может быть запущен на полную мощность в ближайшей перспективе.

Работу по контролю и координации этой деятельности должен осуществлять специальный межведомственный орган (Министерство науки и высшего образования Российской Федерации, Ми-

\section{ЛИТЕРАТУРА}

1. О Стратегии научно-технологического развития Российской Федерации : указ Президента Российской Федерации от 1 декабря 2016 года № 642 ; Об утверждении плана мероприятий по реализации Стратегии научно-технологического развития Российской Федерации : распоряжение Правительства Российской Федерации от 24 июня 2017 года № 1325-р (ред. от 26 сентября 2017 года). - Доступ из справ.-правовой системы «КонсультантПлюс».

2. Паспорт национального проекта «Наука» : утверждён президиумом Совета при Президенте Российской Федерации по стратегическому развитию и национальным проектам, протокол от 24 декабря 2018 года № 16 ; План деятельности Министерства науки и высшего образования Российской Федерации на период с 2019 по 2024 год : утверждён Минобрнауки нистерство промышленности и торговли Российской Федерации, РАН и другие профильные министерства). Ведущая роль здесь должна принадлежать Министерству экономического развития Российской Федерации. На наш взгляд, в составе Правительства Российской Федерации нужно создать отдельную структуру, которая будет осуществлять подобные функции. Тем более что определённая работа в этом направлении, можно сказать, уже ведётся [18]. Предстоит ещё многое сделать, но появляющиеся перспективы внушают оптимизм [19; 20].

С таких позиций научно-технологический прорыв при проведённом внешнем и внутреннем измерении инновационного состояния нашей экономики приобретает новый стратегический контекст. Изложенные меры и инициативы максимально приблизят нашу страну к позиции, с которой и начнётся научно-технологический прорыв. Данная позиция будет ничем иным, как исходным пунктом нового этапа экономического и социального развития. Всё это позволит сформировать благоприятные условия для ускоренного создания на высоком инновационном уровне конкурентоспособной новой продукции для внутреннего и внешнего рынков.

Отсюда можно сделать вывод о том, что разработка и реализация единого плана науки и производства - это действенный механизм научно-технологического прорыва. Можно даже сказать трансформационный механизм российской экономики, механизм её структурной трансформации, в котором формирование направлений и тем научных исследований в нашей стране должно быть связано исключительно с производством и его возможностями в освоении достижений науки.

России 8 февраля 2019 года. - Доступ из справ.-правовой системы «КонсультантПлюс».

3. Распоряжением Правительства Российской Федерации от 28 февраля 2019 года № 348-р утверждён План мероприятий («дорожная карта») по развитию нефтегазохимического комплекса в Российской Федерации на период до 2025 года. - URL: http://www. government.ru

4. Распоряжением Правительства Российской Федерации от 19 марта 2019 года № 466-р утверждена Долгосрочная программа развития открытого акционерного общества «Российские железные дороги» до 2025 года. - URL: http://www.government.ru

5. May B. A. Национальные цели и модель экономического роста : новое в социально-экономической политике России в 2018-2019 гг. / В. А. Мау // Вопросы экономики. - 2019. - № 3. - С. 5-28. 
6. Заседание Совета при Президенте Российской Федерации по науке и образованию от 27 ноября 2018 года. - URL: http://www.kremlin.ru

7. Кочетков С. В. Модель инновационного развития экономики / С. В. Кочетков, О. В. Кочеткова // Вестник Воронежского государственного университета. Серия : Экономика и управление. - 2017. - № 2. - С. 19-24.

8. Кочетков C. В. Инновационный потенциал и пространственное развитие : готова ли российская экономика к прорыву? / С. В. Кочетков, О. В. Кочеткова // Экономист. - 2019. - № 4. - С. 10-24.

9. Российская академия наук (РАН) и Национальная академия наук США подписали соглашение о сотрудничестве. - URL: http://www.ras.ru

10. Перечень поручений по итогам заседания Совета при Президенте Российской Федерации по науке и образованию от 27 ноября 2018 года. - URL: http://www. kremlin.ru

11. О рабочих группах Государственного совета Российской Федерации : распоряжение Президента Российской Федерации от 27 декабря 2018 года № 404-рп. - URL: http://www.kremlin.ru

12. О промышленной политике в Российской Федерации : федеральный закон от 31 декабря 2014 года № 488-Ф3 (ред. от 27 июня 2018 года). - Доступ из справ.-правовой системы «КонсультантПлюс».

13. О промышленных кластерах и специализированных организациях промышленных кластеров : постановление Правительства Российской Федерации от 31 июля 2015 года № 779 (ред. от 02 августа 2018 года). Доступ из справ.-правовой системы «КонсультантПлюс».

14. Об утверждении Стратегии развития тяжёлого машиностроения на период до 2020 года : приказ Министерства промышленности и торговли Российской Федерации от 9 декабря 2010 года № 1150 ; Об утверждении Стратегии развития сельскохозяйственного машиностроения России на период до 2030 года : распоряжение Правительства Российской Федерации от 7 июля 2017 года № 1455-р ; Об утверждении Стратегии развития транспортного машиностроения Рос-

Межрегиональная Санкт-Петербурга и Ленинградской области Общероссийская общественная организаиия «Вольное экономическое общество России»

Кочетков С. В., доктор экономических наук

E-mail:kochetkovsv.75@gmail.com

Кочеткова О. В., кандидат экономических наук E-mail: kochetkova.olesya@bk.ru сийской Федерации на период до 2030 года (вместе с «Планом мероприятий по реализации Стратегии развития транспортного машиностроения Российской Федерации на период до 2030 года») : распоряжение Правительства Российской Федерации от 17 августа 2017 года № 1756-р. - Доступ из справ.-правовой системы «КонсультантПлюс».

15. Московский экономический форум (МЭФ) (г. Москва, Московский государственный университет имени М. В. Ломоносова, 26-27 марта 2014 года). - URL: http://www.me-forum.ru

16. Выступление на I Пленарной дискуссии «Будущее России: вызовы, стратегии, механизмы достижения успеха» МЭФ (г. Москва, РАН, 3-4 апреля 2018 года). URL: http://www.me-forum.ru

17. О стратегическом планировании в Российской Федерации : федеральный закон от 28 июня 2014 г. № 172-Ф3 (в ред. федеральных законов от 23 июня 2016 года № 210-Ф3, от 03 июля 2016 года № 277-Ф3, от 30 октября 2017 года № 299-Ф3, от 31 декабря 2017 года № 507-Ф3). - Доступ из справ.-правовой системы «КонсультантПлюс».

18. О создании инновационного научно-технологического центра «Инновационный научно-технологический центр МГУ «Воробьевы горы» : постановление Правительства Российской Федерации от 28 марта 2019 года № 332. - URL: http://www.government.ru

19. Об утверждении Правил предоставления из федерального бюджета субсидий российским организациям на финансовое обеспечение части затрат на проведение научно-исследовательских, опытно-конструкторских и технологических работ в рамках создания производства газовых турбин большой мощности : постановление Правительства Российской Федерации от 21 марта 2019 года № 301. - URL: http://www. government.ru

20. О предоставлении бюджетных инвестиций публичному акционерному обществу «Объединённая авиастроительная корпорация» : постановление Правительства Российской Федерации от 27 марта 2019 года № 326. - URL: http://www.government.ru

Interregional at the St. Petersburg and Leningrad Region the Free Economic Society of Russia

Kochetkov S. V., Doctor of Sciences in Economics E-mail: kochetkovsv.75@gmail.com

Kochetkova O. V., Candidate of Sciences in Economics

E-mail: kochetkova.olesya@bk.ru 